\title{
Endoscopic Doppler Ultrasound Versus Endoscopic Stigmata-Directed Management of Acute Peptic Ulcer Hemorrhage: A Multimodel Cost Analysis
}

\author{
Victor K. Chen • Richard C. K. Wong
}

Published online: 16 December 2006

(C) Springer Science+Business Media, LLC 2006

The following errors (listed by section, paragraph, and sentence) were published in this article.

\section{Discussion}

In the second to last paragraph (just before the Acknowledgment section) there are two numbers that are missing a zero:

In the fourth sentence " 12,000 new cases" should be "120,000 new cases." In the sixth sentence "\$7 million U.S. dollars" should be "\$70 million U.S. dollars."

The online version of the original article can be found at http://dx.doi.org/10.1007/s10620-006-9506-5

V. K. Chen · R. C. K. Wong $(\bowtie)$

Division of Gastroenterology, Department of Medicine,

University Hospitals Case Medical Center,

11100 Euclid Avenue, Cleveland,

Ohio 44106-5066, USA

e-mail: richard.wong@case.edu 